\title{
ENEA
}

ENTE PER LE NUOVE TECNOLOGIE

L'ENERGIA E L'AMBIENTE

Dipartimento Energia

ENEA_RT-ERG S3-29

SW 9409

\section{MONTE CARLO CALCULATIONS OF FIELD PARAMETERS FOR THE ICRU SPHERE WITH REFERENCE PHOTON BEAMS}

\author{
G. F. GUALDRINI, L. LEMBO, F. MONTEVENTI, F. PADOANI
}

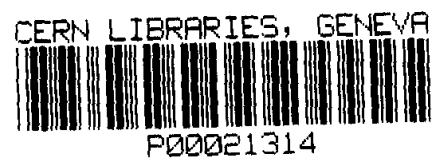




\section{MONTE CARLO CALCULATIONS OF FIELD PARAMETERS FOR THE ICRU SPHERE WITH REFERENCE PHOTON BEAMS}

G. F. GUALDRINI, L. LEMBO, F. MONTEVENTI

ENEA - Dipartimento Ambiente

Centro Ricerche ENEA "Ezio Clementel" di Bologna

F. PADOANI

ENEA - Dipartimento Energia

Centro Ricerche ENEA "Ezio Clementel" di Bologna 
Testo pervenuto nel novembre 1993

I contenuti tecnico-scientifici dei rapporti tecnici dell'ENEA

rispecchianc l'opinione degli autori e non necessariamente quella dell'ente. 


\title{
MONTE CARLO CALCULATIONS OF FIELD PARAMETERS FOR THE ICRU SPHERE WITH REFERENCE PHOTON BEAMS
}

\begin{abstract}
The need to characterise the photon radiation field in the presence of a suitable phantom like the ICRU sphere for the design of personal dosemeters motivated an extensive amount of MCNP Monte Carlo calculations. Air kerma backscatter factors, mean energy of the backscattered radiation relative to angle of the incident beam as well as the backscattered fluence spectra for ISO and BIPM incident reference radiations were calculated for energies between $7 \mathrm{keV}$ and $250 \mathrm{keV}$ and for ${ }^{137} \mathrm{Cs}$ and ${ }^{60} \mathrm{Co}$. Backscatter factor values for different angles of the incident beam were also experimentally evaluated and compared with the corresponding data obtained by Monte Carlo calculations.
\end{abstract}

\section{INTRODUCTION}

After publication by the International Commission on Radiation Units and Measurements of Reports $39^{(1)}$ and $43^{(2)}$ stimulated attention being given to the appropriate procedure for calibrating personal dosemeters.

These calibrations must be performed by placing dosemeters on an appropriate phantom exposed to $X$ and gamma reference radiations as recommended by ISO (International Organization for Standardization) or, in particular cases, to BIPM (Bureau International des Poids et Mesures) reference $X$ ray radiations originally employed for primary calibrations. These $X$ ray beams are characterised by tube voltages ranging from 10 to $300 \mathrm{kV}$ with corresponding mean energies between 7 and $250 \mathrm{keV}$.

The above mentioned reports incited an extensive study on the radiation fields produced by the reference radiations impinging on the ICRU sphere at the ENEA Secondary Standard Dosimetry Laboratory.

These investigations concerned principally:

(1) Determination of air kerma backscatter factors and their dependence on the incident angle of the beam in an expanded and aligned radiation field for the ICRU sphere ${ }^{(3)}$; an extensive comparison of our results with those obtained in other European Laboratories ${ }^{(3,5)}$.

(2) Monte Carlo calculations of spectral physical parameters, i.e. the backscattered radiation mean energy from the ICRU sphere and its dependence on the beam incident angle. Moreover particular attention was devoted to the Monte Carlo evaluation of backscattered radiation spectra in front of the ICRU sphere ${ }^{(6)}$. (3) Comparison of experimental and calculated backscatter factors and their dependence on the beam incident angle using the RS- 1 sphere which is composed of a nearly tissueequivalent material ${ }^{(7)}$. This study enabled the code and its associated interaction coefficients library in the range of energies from $30 \mathrm{keV}$ to ${ }^{60} \mathrm{Co}$ to be validated ${ }^{(8)}$.

\section{COMPUTATIONAL APPROACH}

The code employed in the calculation of the field parameters investigated was the general purpose Monte Carlo code MCNP (Monte Carlo for Neutrons and Photons $)^{(9)}$ developed at the Los Alamos Scientific Laboratory (USA). This code, which makes use of a point-wise cross section library for photons with data derived from Hubbell et a $(10)$ is provided with a very powerful geometry package, allowing complex geometries to be described and with a large variety of variance reduction techniques; in particular Cell Splitting and Russian Roulette are the most commonly used.

The gamma transport was treated taking into account the fluorescent emission and the modification of Thompson and Klein-Nishina differential cross sections by appropriate form factors allowing for electron binding effects.

The mock-up was simplified in the calculation model by neglecting the presence of air. Furthermore, the problems were solved in the so-called kerma approximation, i.e. the secondary electron 


\section{G. F. GUALDRINI, L. LEMBO, F. MONTEVENTI and F. PADOANI}

transport was not taken into account. A more sophisticated treatment, allowing both for the presence of air and for secondary electron transport, is necessary when electronic equilibrium conditions are not fulfilled.

From the point of view of source description, each bremsstrahlung spectrum was taken from the Seelentag Catalogue ${ }^{(1)}$, which has been used in other papers for the same kind of applications. More recently, a new set of $X$ ray spectrum data has been published by Laitano et $a l^{(12)}$. A first comparison demonstrated that this new set of data is generally in good agreement with that of Seelentag but, in some cases, the spectrum mean energy shows differences of up to $3 \%$. Nevertheless some preliminary calculations showed that these differences in mean energy have little effect on backscatter factors.

\section{BACKSCATTER FACTOR CALCULATION}

The first quantity investigated was the air kerma backscatter factor, defined as the ratio of the air kerma values at a given point in the presence and absence of the phantom. The ICRU sphere was chosen as a suitable phantom, however for calibration purposes ICRU has recently proposed using a different phantom. Distances of $0 \mathrm{~cm}$, $0.5 \mathrm{~cm}$ and $1 \mathrm{~cm}$ from the surface of the sphere have been here investigated in order to obtain factors applicable to typical operational and calibration geometry conditions. In addition the same calculations have been performed for various angles of incidence of the radiation beams.

The responses were calculated using boundary crossing estimators. Scoring areas were selected using spheres concentric with the ICRU sphere with radii of $15,15.5$ and $16 \mathrm{~cm}$ and intersecting one-sheet cones with angles increasing by five degrees at a time.

In this way a series of spherical shells was described. The flux (the quantity to be scored) is defined as

$$
\Phi=\mathrm{J} / \bar{\mu}
$$

where $J$ is the current and $\bar{\mu}$ is the average cosine of the angle between the normal to the surface and the direction of the incident particle.

Air kerma has been evaluated using conversion coefficients from photon fluence to air kerma reported by ICRP Publication $51^{(13)}$.

CALCULATION OF FLUENCE BACK-

SCATTERED SPECTRA AND BACKSCATTERED MEAN ENERGY RELATIVE TO ANGLE OF INCIDENT RADIATION

A second computational study was concemed with the calculation of the dependence of the backscattered mean energy on the beam incidence angle, as well as the backscattered radiation spectrum in the presence of the ICRU sphere.

\section{Backscattered mean energy relative to angle of incident radiation}

The quantity to be calculated in terms of MCNP tallies was the mean energy of backscattered radiation $\mathrm{E}_{\mathrm{B}}$,

$$
E_{B}=\frac{\int_{E_{\min }^{\max }}^{E} J(E) E d E}{\int_{E_{\min }^{\max }}^{E} J(E) d E}
$$

where $E_{\min }$ and $E_{\max }$ are the minimum and maximum energies of the photon spectrum, $J(E)$ the photon current and $E$ the photon energy.

MCNP computes the two integrals of the formula as two separate quantities which are correlated. In order to deal with uncorrelated quantities a slight modification was inserted in MCNP to estimate the values of $J(E)$ and $J(E) E$ independently. Separate and independent samples were therefore created for the two estimators, current (which is the photon weight) and current times energy (which is the photon weight times its energy).

The quantities have been scored for eighteen angles, with five-degree angular bins, as for the previous calculations of backscatter factors, thus producing a complete set of backscatter mean energies versus angle.

\section{Energy distribution of backscattered radiation}

The energy distribution of backscattered radiation has been accurately evaluated, bearing in mind the problem of obtaining results with reasonable standard deviation, when backscattered photons were scarce. The goal being a flux distribution in energy bins as narrow as possible, a particular facility supplied by MCNP called DXTRAN had to be employed. The DXTRAN method is a way of obtaining many particles in a small region of interest by creating pseudo-particles. A point detector has been used inside the DXTRAN sphere for the photon flux with a backscattered mean energy greater than $20 \mathrm{keV}$, whilst a boundary crossing tally has been used for the lower energy range. This last approach is motivated by the need, incompatible with the point detector, to take the detailed treatment of photons into account for low energies, i.e. 


\section{MONTE CARLO CALCULATIONS ON ICRU SPHERE}

including fluorescent emission and the modification in the Thompson and Klein-Nishina differential cross sections by form factors allowing for electron binding effects. It has been shown $n^{(14)}$ that for tissue-equivalent materials the detailed treatment is of some importance only for energies lower than $20 \mathrm{keV}$. The scoring area was a $5 \mathrm{~cm}$ radius disc, located in front of the ICRU sphere. The scoring disc dimension, necessary to obtain reasonable standard deviations in acceptable computing time, does not affect the results significantly because at these energies Compton scattering is isotropic and the spectrum is rather independent of the angles of backscattering. Moreover the backscattered component is only slightly shifted in terms of energy compared with the direct radiation component. However, from the practical point of view the knowledge of backscattered spectra at such low energies (where the backscatter factor approaches unity) is not relevant. About half a million source particles were used for each calculation, percentage standard deviations of the order of $2-3 \%$ in the most important energy bins being obtained.

\section{RESULTS}

The air kerma backscatter factors are plotted in Figure 1 against the mean energy of the incident beam. An example of the variation of the backscatter factor with distance from the ICRU sphere for the ISO Narrow Spectrum Series is reported in Figure 2. The percentage standard deviations ( $\%$ SD) were less than $1 \%$, corresponding to one confidence interval, which guarantees a good sampling of each scoring area. Agreement with the results of other authors is within 1.5 standard deviations. It is interesting to point out that the sphere, apart from its intrinsic limitations as a suitable phantom for the calibration of personal dosemeters (in principle only one dosemeter can be calibrated at a time), presents many advantages from the computational point of view. Firstly it is possible to calculate all the angular parameters during the same calculation for one radiation beam. Secondly, by finding an appropriate material (e.g. a plastic material with a very similar absorption coefficient to that of the ICRU sphere in the energy range of interest) operational quantities as defined by ICRU can be obtained directly.

As far as the behaviour of the backscatter data relative to incident angle of radiation is concerned, an example for the $80 \mathrm{kV} \mathrm{X}$ ray beam is reported in Figure 3. The data are interpolated mainly by third degree polynomials and also reported with their absolute standard deviations.

The backscattered contribution at very low energy approaches zero due to the dominating photoelectric absorption. At higher energies, especially for ${ }^{137} \mathrm{Cs}$ and ${ }^{60} \mathrm{Co}$, the dominating diffusion process, being highly forward peaked. causes an enhancement of the backscatter factor for angles approaching $90^{\circ}$, with a corresponding hardening of the backscatter spectrum (Figures 4 and 5). The increase of backscattered mean energy with angle of incident beam is more pronounced by increasing the primary energy, due to the more

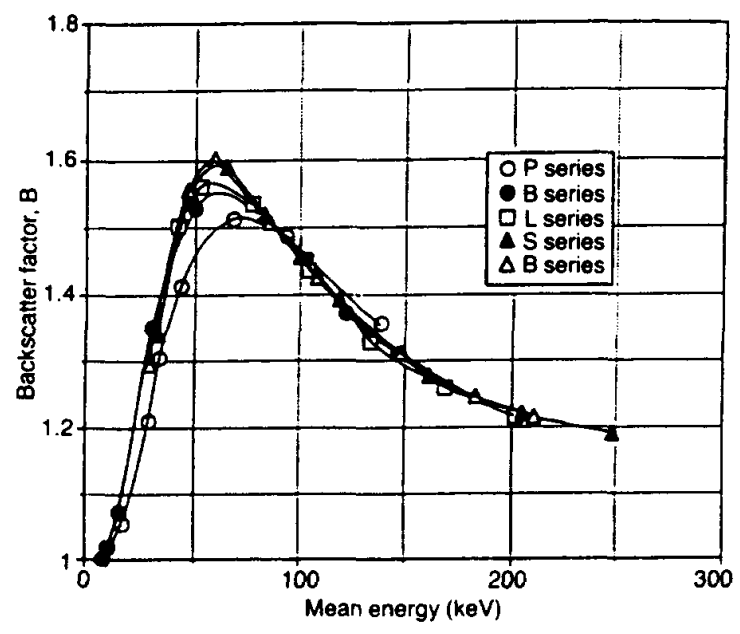

Figure 1. Air kerma backscatter factors at the surface of the ICRU sphere plotted against mean energy of the incident $X$ ray beams for ISO and BIPM reference radiations reported in Table 1.

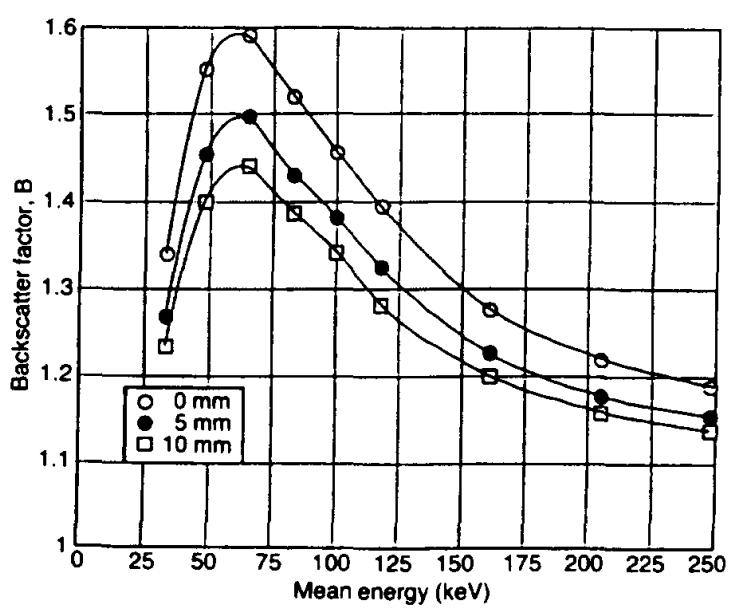

Figure 2. Air kema backscatter factor plotted against mean energy of ISO reference radiation Namow Spectrum Series for various distances from ICRU sphere surface. 


\section{G. F. GUALDRINI, L. LEMBO, F. MONTEVENTI and F. PADOANI}

forward peaked scattering at higher energies (Figures 6 and 7).

The incident $X$ ray spectra as obtained from Seelentag have been merged with the corresponding Monte Carlo calculated backscattered spectra, using the fluence backscatter factor as normalisation coefficient. The plots for the complete Narrow Spectrum Series are reported in Figures 8-16. In Table 1 an overview of the values of the uncollided, backscattered and mixed field mean energies, together with the air kerma backscatter factors are presented for each of the

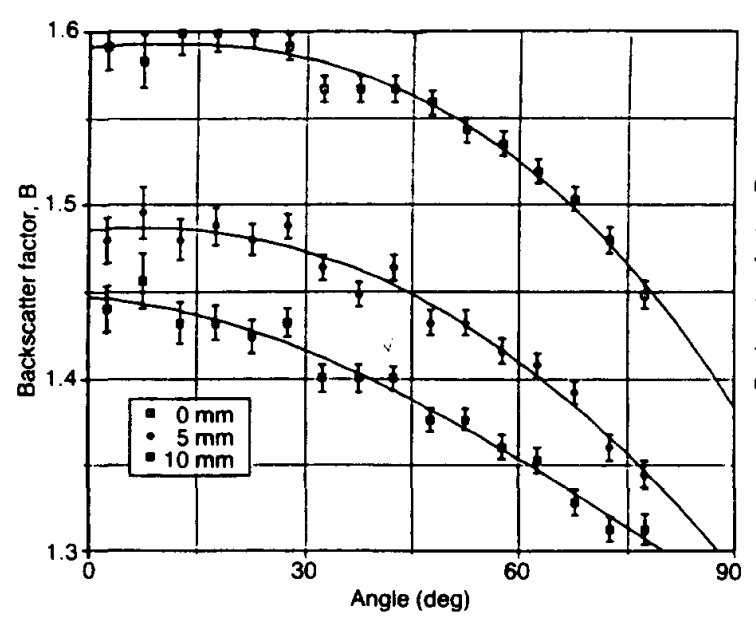

Figure 3. Air kerma backscatter factor plotted against angle of incident beam at various distances from the

ICRU sphere for $80 \mathrm{kV}$ ISO reference radiations.

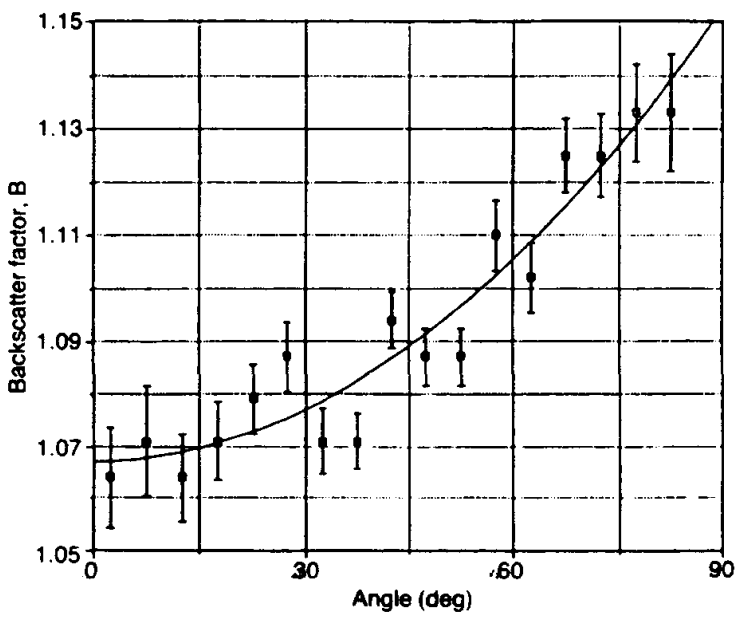

Figure 4. Air kerma backscatter factor plotted against angle of incident beam at the surface of the ICRU sphere for ${ }^{137} \mathrm{Cs}$ ISO reference radiation. different photon beams.

\section{EXPERIMENTAL VALIDATION}

The principal aim of these experimental measurements was the validation of the computational procedure, which has been applied to the calculation of dosimetric quantities, through the comparison of both front and angular backscatter factors for reference photon beams.

The RS-1 sphere $^{(7)}$ was adopted taking into account its optimum characteristics in simulating

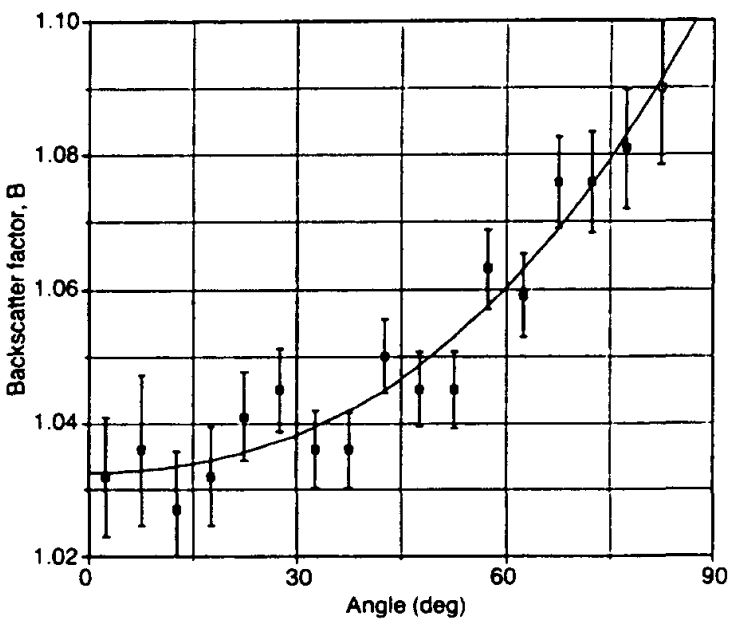

Figure 5. Air kerma backscatter factor plotted against angle of incident beam at the surface of the ICRU sphere for ${ }^{60} \mathrm{Co}$ ISO reference radiation.

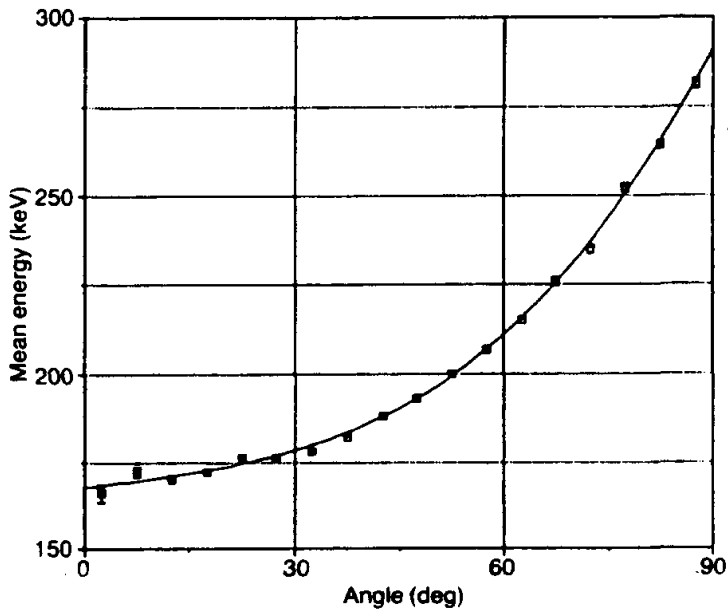

Figure 6. Mean energy of backscattered radiations plotted against angle of incident beam for ${ }^{137} \mathrm{Cs}$ ISO reference radiation. 


\section{MONTE CARLO CALCULATIONS ON ICRU SPHERE}

the ICRU material in the energy region of interest. The experimental set-up has been designed in order to minimise the scattered radiation produced by sources different from the spherical phantom (see Figure 17).

Each particular measurement has been normalised to a constant tube voltage value using

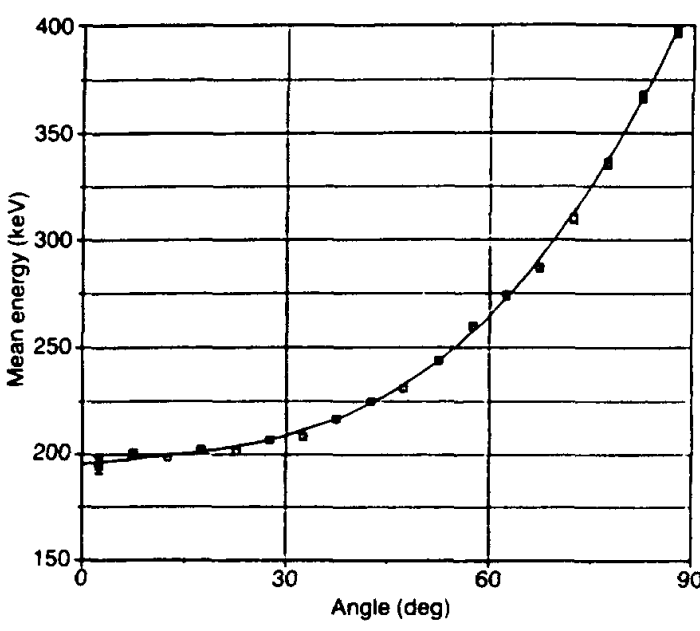

Figure 7. Mean energy of backscattered radiations plotted against angle of incident beam for ${ }^{60} \mathrm{Co}$.

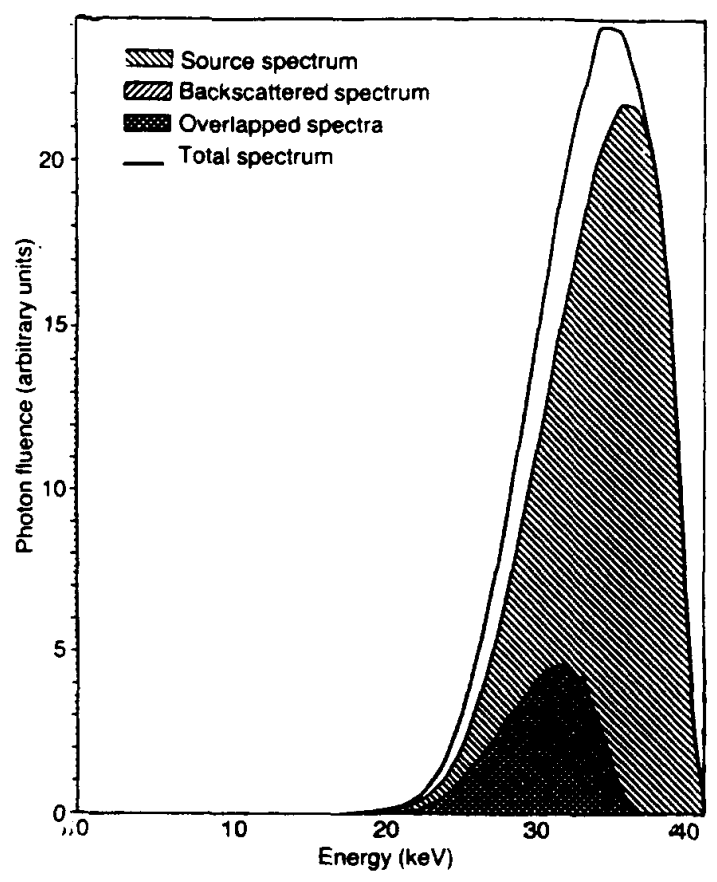

Figure 8. Photon spectra at $1 \mathrm{~cm}$ from the ICRU sphere surface. Narrow spectrum $40 \mathrm{kV}$ ISO incident beam. the readout values given by a main monitor chamber and, in presence of the phantom through the use of an additional monitor chamber. The air kerma values $D_{a}$ in the absence and $D_{\text {ph }}$ in the presence of the phantom have been respectively obtained in the following way:

$D_{a}=(1 / n) \sum_{n}\left(D F_{E} F_{t p} / M_{1} F_{t p}\right)=(1 / n) F_{E} \sum_{n}\left(D / M_{1}\right)$

$D_{p h}=\left\{(1 / n) \Sigma_{n}\left[D /\left(M_{1}-M_{2}\right)\right]-D / F_{E}\right\} F_{E}$

where $\mathbf{n}=$ number of measurements, $\mathrm{D}=$ air kerma as measured by the reference chamber, $M_{1}=$ read-out of the main monitor chamber, $M_{2}=$ readout of the additional monitor chamber, $\mathrm{F}_{t \mathrm{p}}=$ air density correction factor (temperature and pressure), $F_{E}=$ calibration factor for mean energy $E$ of the primary beam, and $F_{E^{\prime}}=$ calibration factor for mean energy $E^{\prime}$ of the backscattered radiation as determined by the Monte Carlo calculation.

The main sources of uncertainty related to the backscatter factor measurements are due to the following factors:

(a) statistical fluctuations on the reproducibility of the ionisation chamber response,

(b) evaluation of the factor $\mathrm{F}_{\mathrm{E}^{\prime}}$ due to the broad energy distribution of the backscattered spectra,

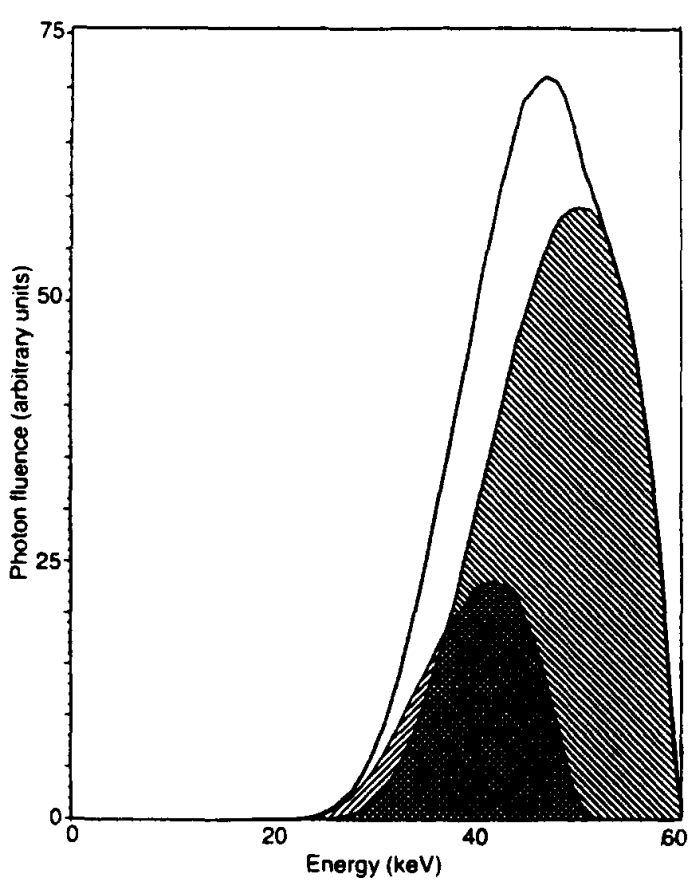

Figure 9. Photon spectra at $1 \mathrm{~cm}$ from the ICRU sphere surface. Narrow spectrum $60 \mathrm{kV}$ ISO incident beam. Key as Figure 8. 


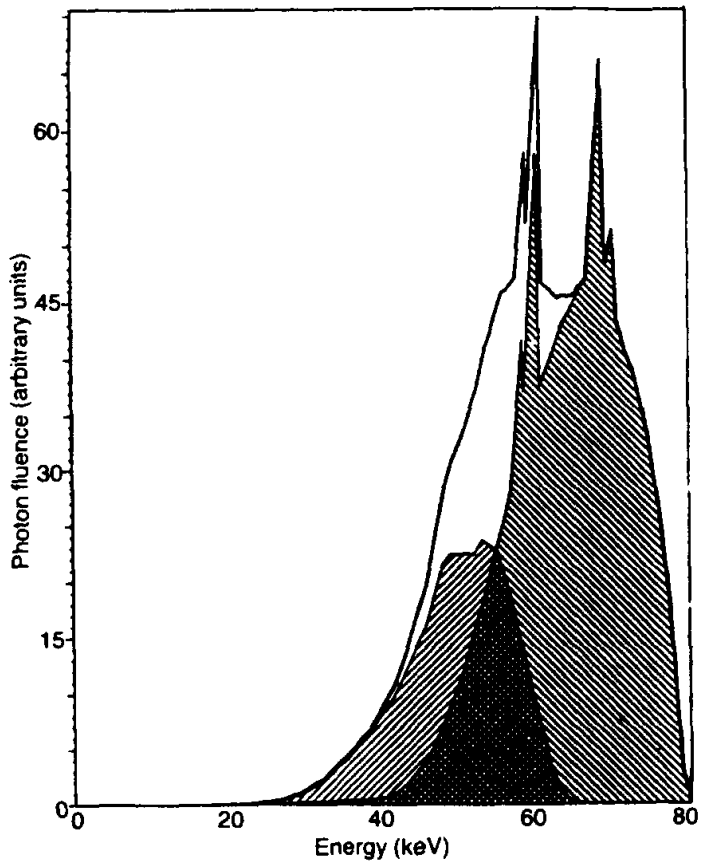

Figure 10. Photon spectra at $1 \mathrm{~cm}$ from the ICRU sphere surface. Narrow spectrum $80 \mathrm{kV}$ ISO incident beam. Key as Figure 8.

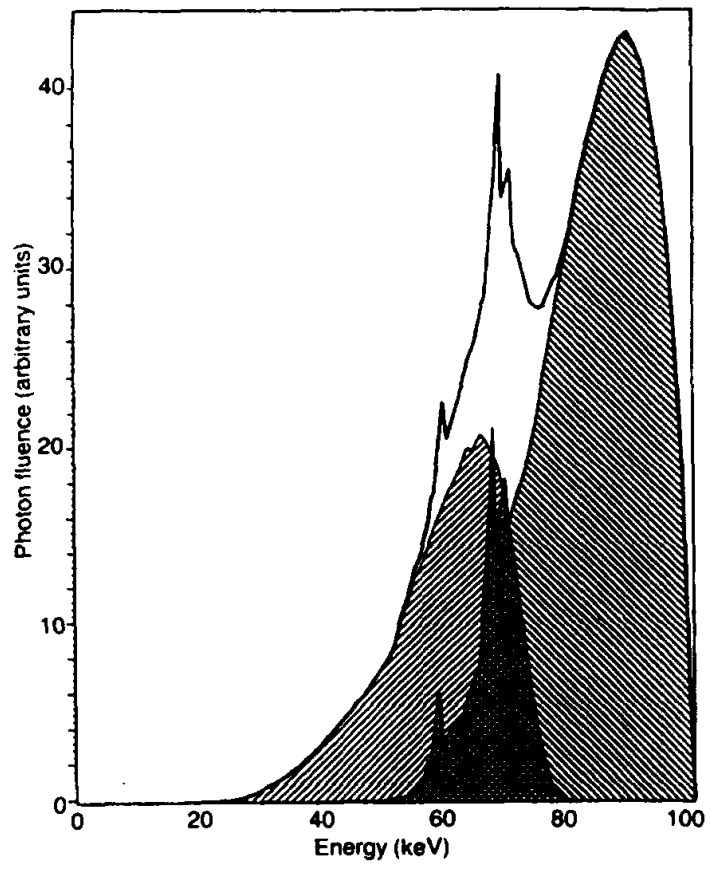

Figure 11. Photon spectra at $1 \mathrm{~cm}$ from the ICRU sphere surface. Narrow spectrum $100 \mathrm{kV}$ ISO incident beam. Key as Figure 8.

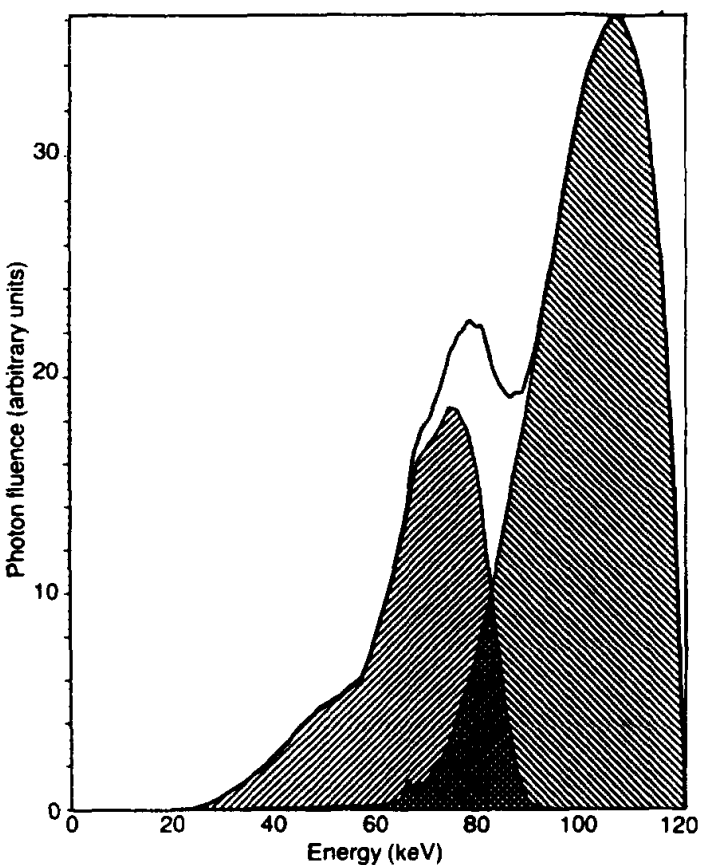

Figure 12. Photon spectra at $1 \mathrm{~cm}$ from the ICRU sphere surface. Narrow spectrum $120 \mathrm{kV}$ ISO incident beam. Key as Figure 8.

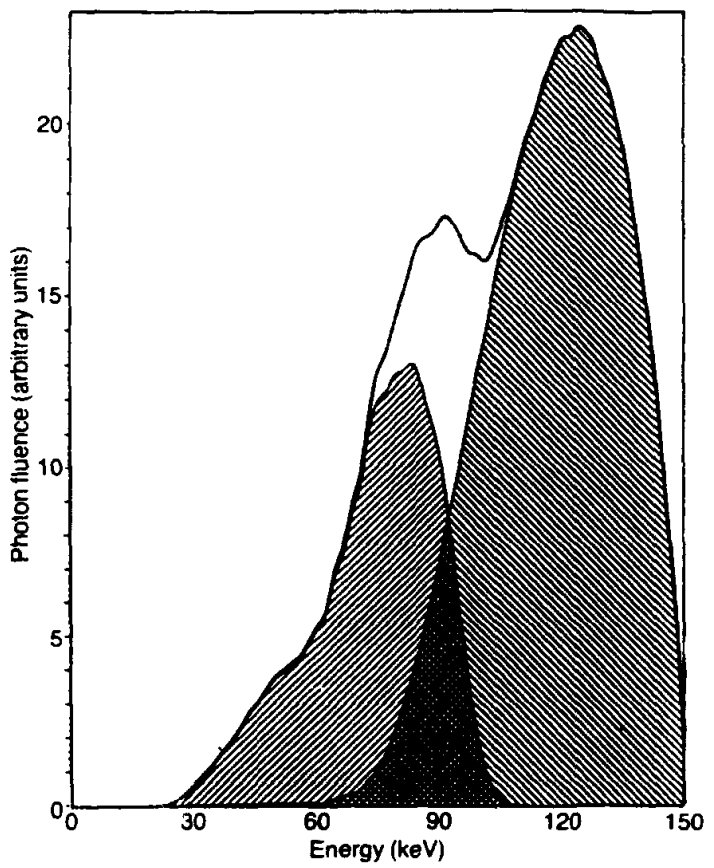

Figure 13. Photon -spectra at $1 \mathrm{~cm}$ trom the ICRU sphere surface. Narrow spectrum $150 \mathrm{kV}$ ISO incident beam. Key as Figure 8. 


\section{MONTE CARLO CALCULATIONS ON ICRU SPHERE}

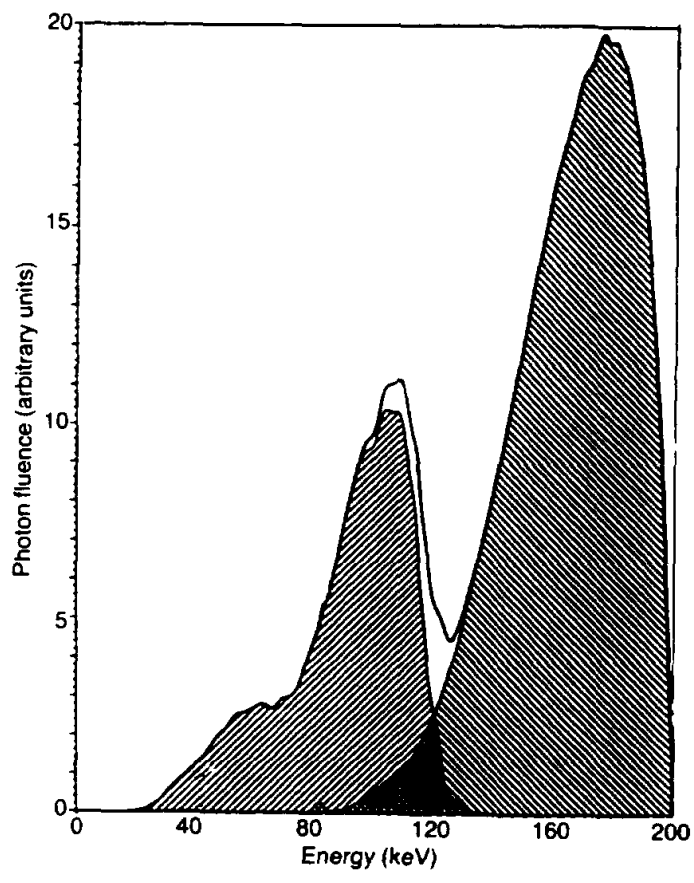

Figure 14. Photon spectra at $1 \mathrm{~cm}$ from the ICRU sphere surface. Narrow spectrum $200 \mathrm{kV}$ ISO incident beam. Key as Figure 8.

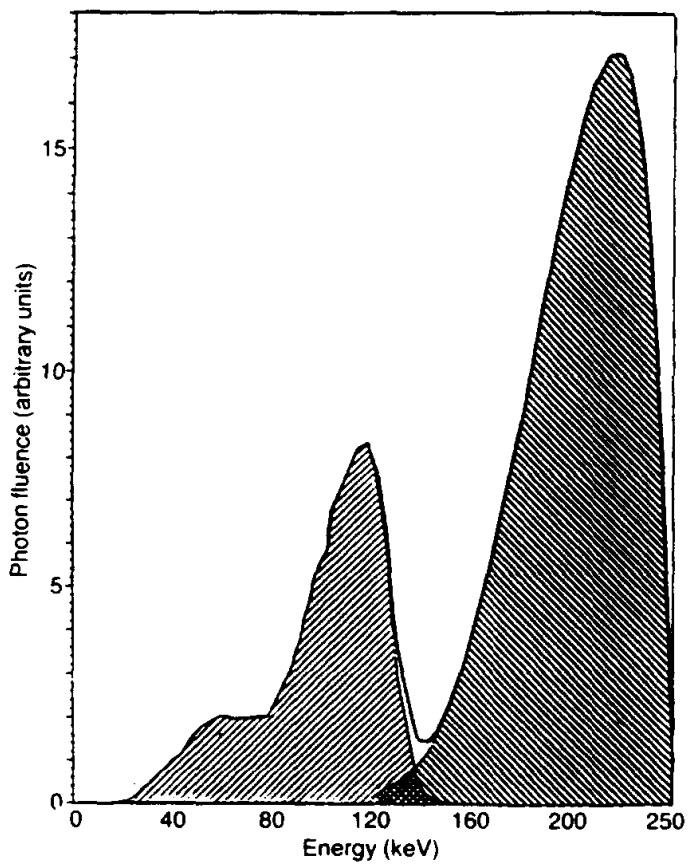

Figure 15. Photon spectra at $1 \mathrm{~cm}$ from the ICRU sphere surface. Narrow spectrum $250 \mathrm{kV}$ ISO incident beam. Key as Figure 8. (c) determination of the measuring point in front of the phantom by means of the ionisation chamber.

The main source of uncertainty is related to point (c), and has been evaluated using the results of Monte Carlo calculations concerning variation of the backscatter factor with the distance $d$ from the surface of the phantom.

In Table 2 the complete set of measurements for the front backscatter factor is compared with corresponding calculations. Accuracy improves with increasing the 'beam air kerma rate' as in the case of the BIPM series and the High Kerma Rate series; the total errors are usually within $\pm 1 \%$. This comparison shows that the percentage deviations between the experimental and calculated

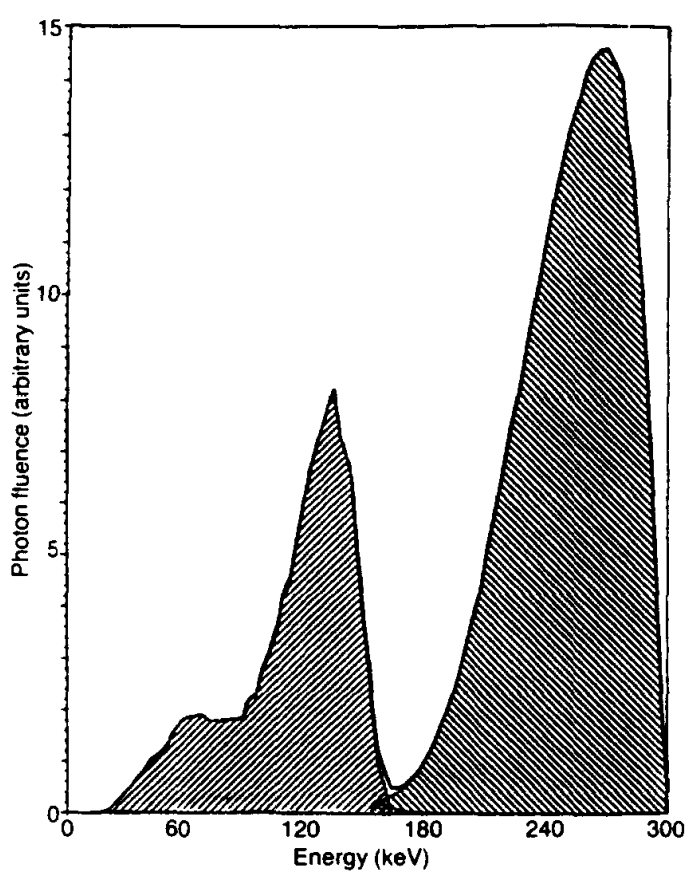

Figure 16. Photon spectra at $1 \mathrm{~cm}$ from the ICRU sphere surface. Nartow spectrum $300 \mathrm{kV}$ ISO incident beam.

Key as Figure 8.

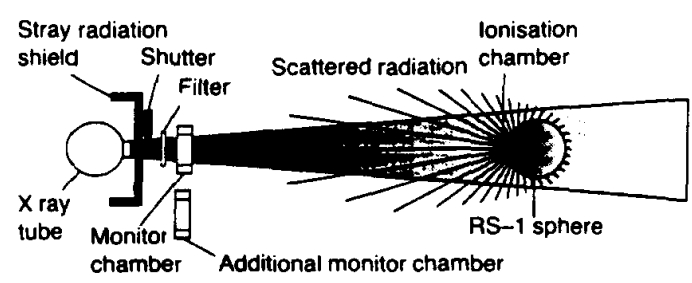

Figure 17. Experimental equipment employed for the backscattering measurements with RS-1 sphere. 


\section{G. F. GUALDRINI, L. LEMBO, F. MONTEVENTI and F. PADOANI}

Table 1. Calculated air kerma backscatter factors and values of mean energies for uncollided incident radiations, backscattered radiations and combined incident and backscattered radiations for the four series of ISO reference radiations and for the BIPM reference radiations.

\begin{tabular}{|c|c|c|c|c|c|c|c|c|c|c|}
\hline $\begin{array}{l}\text { BIPM } \\
\text { (P) }\end{array}$ & $\begin{array}{l}\text { Voltage (kV) } \\
\text { Uncollided mean energy (keV) } \\
\text { Backscattered mean energy (keV) } \\
\text { Total mean energy (keV) } \\
\text { Backscatter factor }\end{array}$ & $\begin{array}{r}10 \\
8 \\
8 \\
8 \\
1\end{array}$ & $\begin{array}{c}25 \\
17 \\
17.8 \\
17 \\
1.053\end{array}$ & $\begin{array}{l}30 \\
17.3 \\
19.5 \\
17.4 \\
1.047\end{array}$ & $\begin{array}{r}50 \\
30 \\
29 \\
29.9 \\
1.208\end{array}$ & $\begin{array}{c}50 \\
34 \\
32 \\
34.4 \\
1.305\end{array}$ & $\begin{array}{c}100 \\
50 \\
44 \\
49 \\
1.414\end{array}$ & $\begin{array}{r}135 \\
68 \\
52.5 \\
64 \\
1.514\end{array}$ & $\begin{array}{c}180 \\
81 \\
58 \\
75 \\
1.493\end{array}$ & $\begin{array}{r}250 \\
118 \\
73 \\
80 \\
1.386\end{array}$ \\
\hline $\begin{array}{l}\text { High air } \\
\text { Kerma } \\
\text { rate } \\
\text { (A) }\end{array}$ & $\begin{array}{l}\text { Voltage (kV) } \\
\text { Uncollided mean energy (keV) } \\
\text { Backscattered mean energy (keV) } \\
\text { Total mean energy (keV) } \\
\text { Backscatter factor }\end{array}$ & $\begin{array}{c}10 \\
7.5 \\
7.7 \\
7.5 \\
1\end{array}$ & $\begin{array}{c}20 \\
12.9 \\
14 \\
12.9 \\
1.019\end{array}$ & $\begin{array}{r}30 \\
19.7 \\
20.6 \\
19.7 \\
1.073\end{array}$ & $\begin{array}{r}60 \\
38 \\
34.5 \\
37.5 \\
1.351\end{array}$ & $\begin{array}{c}100 \\
58 \\
47 \\
55.3 \\
1.527\end{array}$ & $\begin{array}{c}200 \\
96 \\
64 \\
86.5 \\
1.461\end{array}$ & $\begin{array}{c}250 \\
119 \\
73 \\
105 \\
1.383\end{array}$ & $\begin{array}{c}280 \\
146 \\
83 \\
127 \\
1.310\end{array}$ & $\begin{array}{r}300 \\
147 \\
83 \\
128 \\
1.306\end{array}$ \\
\hline $\begin{array}{l}\text { Wide } \\
\text { spectrum } \\
\text { (L) }\end{array}$ & $\begin{array}{l}\text { Voltage (kV) } \\
\text { Uncollided mean energy (keV) } \\
\text { Backscattered mean energy (keV) } \\
\text { Total mean energy (keV) } \\
\text { Backscatter factor }\end{array}$ & $\begin{array}{c}60 \\
45 \\
38.5 \\
43.6 \\
1.505\end{array}$ & $\begin{array}{c}80 \\
56 \\
46 \\
53.4 \\
1.565\end{array}$ & $\begin{array}{r}110 \\
78 \\
57 \\
72 \\
1.535\end{array}$ & $\begin{array}{r}150 \\
104 \\
69 \\
93 \\
1.436\end{array}$ & $\begin{array}{r}200 \\
137 \\
83 \\
121 \\
1.330\end{array}$ & $\begin{array}{r}250 \\
174 \\
95 \\
151 \\
1.257\end{array}$ & $\begin{array}{c}300 \\
207 \\
104 \\
179 \\
1.216\end{array}$ & & \\
\hline $\begin{array}{l}\text { Narrow } \\
\text { spectrum } \\
\text { (S) }\end{array}$ & $\begin{array}{l}\text { Voltage (kV) } \\
\text { Uncollided mean energy (keV) } \\
\text { Backscattered mean energy (keV) } \\
\text { Total mean energy (keV) } \\
\text { Backscatter factor }\end{array}$ & $\begin{array}{l}40 \\
33 \\
29.7 \\
32.5 \\
1.339\end{array}$ & $\begin{array}{l}60 \\
47 \\
40 \\
45 \\
1.551\end{array}$ & $\begin{array}{r}80 \\
65 \\
50 \\
61 \\
1.591\end{array}$ & $\begin{array}{r}100 \\
83 \\
60 \\
76 \\
1.519\end{array}$ & $\begin{array}{c}120 \\
100 \\
68 \\
90 \\
1.456\end{array}$ & $\begin{array}{c}150 \\
117 \\
75 \\
104 \\
1.393\end{array}$ & $\begin{array}{c}200 \\
163 \\
93 \\
142 \\
1.276\end{array}$ & $\begin{array}{l}250 \\
207 \\
105 \\
179 \\
1.224\end{array}$ & $\begin{array}{l}300 \\
248 \\
115 \\
210 \\
1.190\end{array}$ \\
\hline $\begin{array}{l}\text { Low air } \\
\text { kerma } \\
\text { rate } \\
\text { (B) }\end{array}$ & $\begin{array}{l}\text { Voltage (kV) } \\
\text { Uncollided mean energy (keV) } \\
\text { Backscattered mean energy (keV) } \\
\text { Total mean energy (keV) } \\
\text { Backscatter factor }\end{array}$ & $\begin{array}{c}35 \\
30 \\
27.6 \\
30 \\
1.296\end{array}$ & $\begin{array}{c}55 \\
47 \\
39.5 \\
45 \\
1.557\end{array}$ & $\begin{array}{r}70 \\
60 \\
47.5 \\
57 \\
1.602\end{array}$ & $\begin{array}{r}100 \\
86 \\
61.5 \\
79 \\
1.507\end{array}$ & $\begin{array}{r}125 \\
108 \\
71 \\
95 \\
1.425\end{array}$ & $\begin{array}{r}170 \\
146 \\
86 \\
127 \\
1.312\end{array}$ & $\begin{array}{c}210 \\
184 \\
99 \\
160 \\
1.245\end{array}$ & $\begin{array}{c}240 \\
211 \\
107 \\
182 \\
1.216\end{array}$ & \\
\hline
\end{tabular}

Table 2. Comparison of calculated and measured air kerma backscatter factors at $1 \mathrm{~cm}$ distance from the RS-1 sphere for some BIPM and ISO reference radiations.

\begin{tabular}{|c|c|c|c|c|c|c|c|c|}
\hline $\begin{array}{l}\text { BIPM } \\
\text { series }\end{array}$ & $\begin{array}{l}\text { Voltage (kV) } \\
\text { Experiment } \\
\text { Calculation }\end{array}$ & $\begin{array}{c}50 \\
1.191 \\
(0.5 \%)^{*} \\
1.204 \\
(1 \%)\end{array}$ & $\begin{array}{c}100 \\
1.300 \\
(0.7 \%) \\
1.295 \\
(1 \%)\end{array}$ & $\begin{array}{c}135 \\
1.367 \\
(0.7 \%) \\
1.375 \\
(1 \%)\end{array}$ & $\begin{array}{c}180 \\
1.345 \\
(0.5 \%) \\
1.350 \\
(1 \%)\end{array}$ & $\begin{array}{c}250 \\
1.261 \\
(0.6 \%) \\
1.268 \\
(1 \%)\end{array}$ & & \\
\hline $\begin{array}{l}\text { High air } \\
\text { kerma rate } \\
\text { series }\end{array}$ & $\begin{array}{l}\text { Voltage (kV) } \\
\text { Experiment } \\
\text { Calculation }\end{array}$ & $\begin{array}{c}20 \\
1.011 \\
(0.3 \%) \\
1.020 \\
(1 \%)\end{array}$ & $\begin{array}{c}30 \\
1.046 \\
(0.2 \%) \\
1.064 \\
(1 \%)\end{array}$ & $\begin{array}{c}60 \\
1.222 \\
(0.8 \%) \\
1.242 \\
(1 \%)\end{array}$ & $\begin{array}{c}100 \\
1.363 \\
(0.8 \%) \\
1.383 \\
(1 \%)\end{array}$ & $\begin{array}{c}200 \\
1.307 \\
(0.6 \%) \\
1.315 \\
(1 \%)\end{array}$ & $\begin{array}{c}250 \\
1.260 \\
(0.5 \%) \\
1.264 \\
(1 \%)\end{array}$ & $\begin{array}{c}300 \\
1.221 \\
(0.4 \%) \\
1.224 \\
(1 \%)\end{array}$ \\
\hline $\begin{array}{l}\text { Wide spectrum } \\
\text { series }\end{array}$ & $\begin{array}{l}\text { Voltage (kV) } \\
\text { Experiment } \\
\text { Calculation }\end{array}$ & $\begin{array}{c}60 \\
1.315 \\
(2.4 \%) \\
1.357 \\
(1 \%)\end{array}$ & $\begin{array}{c}80 \\
1.395 \\
(1.2 \%) \\
1.405 \\
(1 \%)\end{array}$ & $\begin{array}{c}110 \\
1.383 \\
(1.2 \%) \\
1.387 \\
(1 \%)\end{array}$ & $\begin{array}{c}150 \\
1.314 \\
(0.8 \%) \\
1.321 \\
(1 \%)\end{array}$ & $\begin{array}{c}200 \\
1.241 \\
(0.6 \%) \\
1.246 \\
(1 \%)\end{array}$ & $\begin{array}{c}250 \\
1.194 \\
(0.3 \%) \\
1.190 \\
(1 \%)\end{array}$ & $\begin{array}{c}300 \\
1.165 \\
(0.3 \%) \\
1.163 \\
(1 \%)\end{array}$ \\
\hline${ }^{137} \mathrm{Cs}$ & $\begin{array}{l}\text { Energy (keV) } \\
\text { Experiment } \\
\text { Calculation }\end{array}$ & $\begin{array}{c}662 \\
-(*)) \\
1.049 \\
(0.8 \%)\end{array}$ & & & & & & \\
\hline${ }^{60} \mathrm{Co}$ & $\begin{array}{l}\text { Energy (keV) } \\
\text { Experiment } \\
\text { Calculation }\end{array}$ & $\begin{array}{c}1250 \\
1.027 \\
(0.3 \%) \\
1.018 \\
(1 \%)\end{array}$ & & & & & & \\
\hline
\end{tabular}

* Figure within brackets is one percentage standard deviation

* The measurement was not carried out due to the too low air kerma rate of the available source. 


\section{MONTE CARLO CALCULATIONS ON ICRU SPHERE}

deviations between the experimental and calculated values are generally less than $\pm 1 \%$.

Furthermore, some measurements were carried out in order to measure the angular variation of the backscatter factors, and the results were compared with corresponding Monte Carlo calculations, good agreement being obtained.

\section{CONCLUSION}

All the calculations carried out demonstrated the ability of the Monte Carlo code MCNP for solving dosimetric problems mainly related to quantities which cannot be directly measured

In particular, real photon fields were calculated in terms of fluence spectra in the presence of the ICRU sphere for an incident angle $0^{\circ}$ for different irradiation conditions with ISO and BIPM reference radiations. The results have shown that the higher the mean energy of the photon beam and the higher the beam filtering, the greater is the modification of the original incident field. reaching the bi-modal photon energy distribution (see Figures 14, 15 and 16). This behaviour can have a significant influence on the design of dosemeters, in order to obtain the optimum energy response in the whole energy region of interest. To the same end useful information can be obtained from the Monte Carlo results as regards the influence on the backscattered radiation of both the angle of the incident radiation and the distance from the surface of the ICRU sphere.

Comparison of calculations and measurements, both for backscatter factors and backscattered mean energies, besides validating the MCNP Monte Carlo code, confirmed that the RS-1 material can be considered as a good substitute of the ICRU material in the range of energies investigated.

\section{ACKNOWLEDGEMENT}

This work has been carried out under the CEC contract n.B160347 in the framework of EURADOS WG4 (Computational Dosimetry) activities. We wish to thank Dr K. W. Burn for his useful advice on the use of the MCNP code.

\section{REFERENCES}

1. ICRU. Determination of Dose Equivalents Resulting from External Radiation Sources. Publication 39 (Bethesda Maryland: ICRU Publications) (1985).

2. ICRU. Determination of Dose Equivalents Resulting from External Radiation Sources. Part 2 Publication 43 (Bethesda Maryland: ICRU Publications) (1988).

3. Gualdrini, G. F. Field Parameters and Operational Quantities for the ICRU Sphere with Reference Photon Beams. Part 1. Monte Carlo Calculations of Angular Dependence of Backscatter Factors. (ENEA RT/AMB/92/12) (in press).

4. Dimbylow, P. J., Francis, T. M. and Bartlett, D. T. Calibration of Photon Personal Dosemeters in Terms of the ICRU Operational Quantities: Calculations of Phantom Backscatter and Depth Dose Distributions. NRPB R230 (London: HMSO) (1990).

5. Bohm. J. and Grosswendt, B. 10 Years of Intercomparison Measurements of Dosemeter Systems for the Individual Monitoring of Photon and Beta Radiation - Retrospective View. New Data and Perspectives. PTB Mitteilungen 99 2/89 (1989).

6. Gualdrini, G. F., Padoani, F. and Morelli, B. Field Parameters and Operational Quantities for the ICRU Sphere with Reference Photon Beams. Part 2 Monte Carlo Calculations of Backscattered Spectra and Backscattered Mean Energy Angular Distribution. (ENEA RT/AMB/92/13) (in press).

7. Hermann, K. P. and Harder, D. Production and Use of a Polyethylene-based Tissue-equivalent Spherical Phantom Substituting the ICRU Sphere for Photons. Radiat. Prot. Dosim. 28, 73-76 (1989).

8. Gualdrini, G. F.. Monteventi, F. and Sermenghi, I. Field Parameters and Operational Quantities for the ICRU Sphere with Reference Photon Beams. Part 3 Experimental and Computational Analyses on the Tissue Substitute Material RS-1. ENEA REPORT 1992 (in press).

9. MCNP. A General Monte Carlo Code for Neutron and Photon Transport. LA-7396 Rev. 2 Los Alamos (1986).

10. Hubbell, J. H., Veigele, W. J., Briggs, E. A., Brown, R. T. Cromer, D. T. and Howerton, R. J. Atomic Form Factors, Incoherent Scattering Functions and Photon Scattering Cross Sections. J. Phys. Chem. Ref. Data 4. 471 (1975).

11. Seelentag, W. W., Panzer, W., Drexler, G., Platz, L. and Santner. F. A Catalogue of Spectra used for the Calibration of Dosemeters. GSF-Bericht S-560 (March 1979).

12. Laitano, F., Toni, M. P., Pani, R. and Pellegrini, R. Energy Distributions and Air Kerma Rates of ISO and B.I.P.M. Reference Filtered X-Radiations. ENEA REP (December 1990).

13. ICRP. Data for Use in Protection Against External Radiation. Publication 51 (Oxford: Pergamon Press) (1987).

14. Nelson, R. F. and Chilton, A. B. Low Energy Photon Dose Deposition in Tissue Slab and Spherical Phantoms. (U.S. Nuclear Regulatory Commission Washington DC 20555) NUREG/CR-3425 (1983) 
Edito a cura dell'ENEA, Direzione Relazioni Esterne

Viale Regina Margherita, 125 - Roma

Finito di stampare nel mese di dicembre 1993

presso il Laboratorio Tecnografico 